\title{
Energy saving in road tunnels by means of transparent tension structures
}

\author{
A. Peña García ${ }^{1}$, L.M. Gil-Martín ${ }^{2}$, A. Espín Estrella ${ }^{1}$ and F. Aznar Dols ${ }^{1}$ \\ ${ }^{1}$ Department of Civil Engineering. \\ ETSICCP, University of Granada. \\ Campus Fuentenueva - 18071 Granada (Spain) \\ Phone number:+0034 958249 435, e-mail: pgarcia@ugr.es, aespin@ugr.es, faznar@ugr.es \\ ${ }^{2}$ Department of Structural Mechanics. \\ ETSICCP, University of Granada. \\ Campus Fuentenueva - 18071 Granada (Spain) \\ Phone number:+0034 249 962, e-mail: mlgil@ugr.es
}

\begin{abstract}
The high and constant rate of energy consumption in road tunnels has led researchers to look for more and more efficient lamps and luminaries. The solutions developed have partially contributed to energy saving but consumption is still high, specially in the threshold zone which requires very high levels of luminance, and the solutions found still have important contras like colour performance. In this work, we present a completely different solution: the extension of the "threshold zone" out of the tunnel by means of a transparent tension structure to let visible solar radiation go into the tunnel and achieve the required levels of luminance during daytime without any kind of electrical lighting.
\end{abstract}

\section{Keywords}

Energy Saving, Solar Radiation, Lighting, Road Tunnel, Safety.

\section{Introduction}

Road tunnel lighting is one of the most complex problems in electrical lighting [1]. The high impact of lighting in safety is even more important when dealing with tunnels because of different eventualities. There are three main kinds of problems that can arise when dealing with tunnel lighting:

- Maintenance problems, like replacement of lamps, effects of pollution on luminaries, road and walls...

- Psychological problems that concern the lack of attention from the side of the driver. This lack of attention may arise due to different factors such as flickering, effect of bright or dark cells (leading to claustrophobia) and many other.
- Physiological problems, like visual adaptation and other that are not well understood yet [2, $3]$. One of the most important is melatonin suppression [4, 5] and its impact on the human circadian system. The absolute and spectral sensitivities to light by the human circadian system are behind of many alterations and disorders on the health of people exposed to high levels of illuminance during night time. It is a well-know fact that melatonin is released only during night time and the exposure to light above a given threshold can suppress this release thus breaking the circadian rhythm. The spectral composition of the light sources used for lighting during nigh time, specially for very long road tunnels, must be carefully chosen in order to avoid this kind of distortions that may lead to serious physiological consequences [6 - 8].

Most of these problems can be solved by means of an accurate lighting, specially during daytime, that help the driver to get adapted to the levels of luminance [9 12] inside the tunnels with no negative effect.

The achievement of such lighting requires permanent working of quite powerful luminaries or projectors whose consumption trough the year can be extremely high in both economical and environmental terms. These high costs are especially dramatic in the so called "threshold zone" of the tunnel, which is the first one immediately after the gate and, hence, the most consuming one for evident reasons of visual adaptation during daytime. The level of luminance required in the zones after the threshold one is much smaller as shown in Figure 1. 


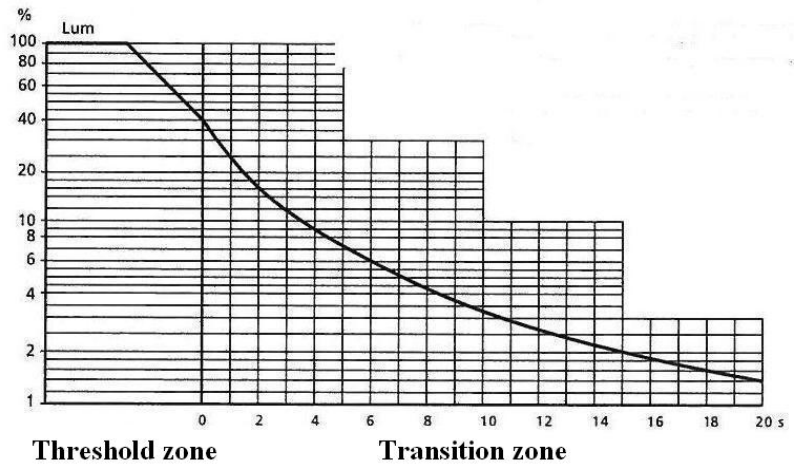

Fig. 1. Luminance level in threshold and transition zones.

This high impact, urgently demands friendly environmental solutions that, as proved in this work, may arise from an intelligent use of sunlight.

The main objective of this work is to prove that transparent tension structures at the gate of one road tunnel allow using the sunlight with a significant energy spare. Besides the interesting applications in matter of visual performance and Civil Engineering, the main objectives of this work are the following:

- Energy saving.

- Saving in the number of luminaries and lamps with the consequent reduction on the environmental impact (industrial waste, $\mathrm{CO}_{2}$ emissions, recycling ...).

- Saving in building materials through the implementation of tension structures, which are cheaper than concrete or cement.

\section{Materials and Method}

In order to achieve the relevant levels of illumination with a significant energy saving, the threshold zone of a road tunnel in Granada (Spain) has been expanded out of the tunnel by means of one transparent tension structure set at the beginning of the tunnel. The main parameters of this tension structure (length, curvature, shape...) must be carefully calculated in order to ensure an optimal performance and life even in conditions of adverse weather (rain, snow) or, on the other hand, long exposures to high levels of insolation because climate in Granada goes from very cold winters to very hot and sunny summers with short springs and falls.

Its shape must also avoid the accumulation of snow or water and ensure an easy maintenance (see Fig. 2).

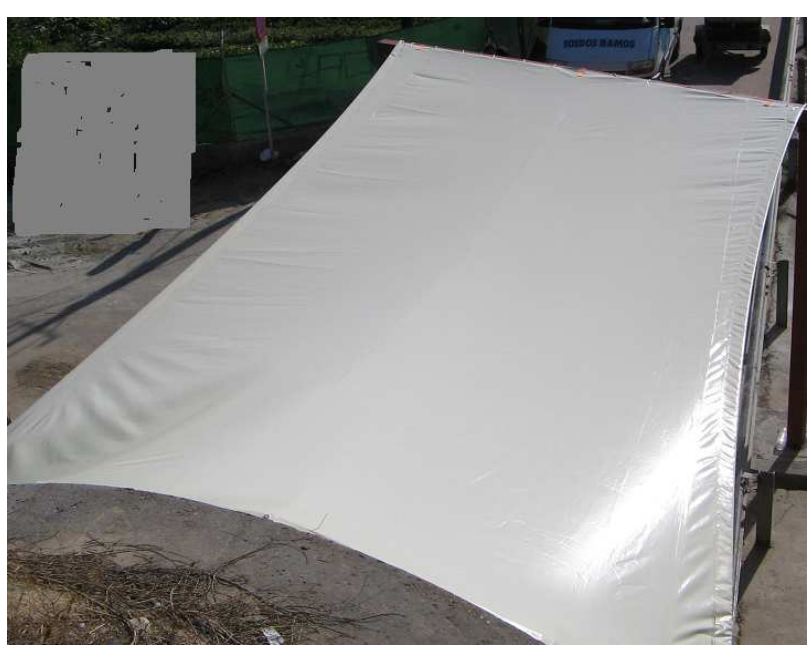

Fig. 2. Upper view of the tension structure set in the gate of the tunnel.

In addition to the relevant mechanical and building constrains, the optical properties (mainly transmittance and colour) are an extremely important parameter to consider before choosing the material for the tension structure.

Indeed, a weak structure with good optical properties is as useless as a strong structure that can not transmit the amount of light needed for our purposes.

Finally, the optimal compromise between optical and mechanical parameters has been found for polyester with PVC coating, whose transmittance is shown in Figure 3.

\section{Transmittance Vs. Wavelength}

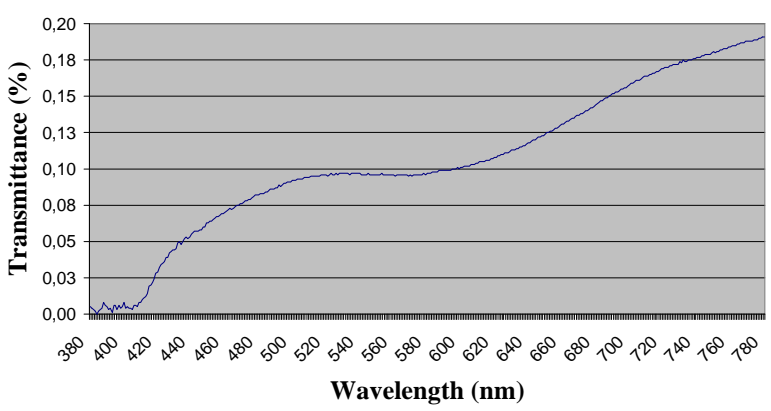

Fig. 3. Transmittance of the material chosen for the tension structure in the range of visible light. 
The theoretical values of luminance (which is the photometric quantity corresponding to the bright of one given surface and is expressed in candela $/ \mathrm{m}^{2}$ ) and illuminance (which is the photometric quantity corresponding to the incident power on one given surface and is expressed in lux $=$ lumen $/ m^{2}$ ) under the tension structure have been calculated with the $L_{20}$ method. This method, which is the most used for calculations of tunnel lighting, is widely described in most of the publications on tunnel lighting [1, 9-12].

The $L_{20}$ method establishes that the luminance in the threshold zone is:

$$
L_{t h}=k L_{20}
$$

where the factor $k$ varies between 0.05 and 0.10 depending on the maximum speed allowed within the road tunnel.

In equation (1), $L_{20}$ is the luminance within a cone of $20^{\circ}$ centred in the gate of the tunnel. It is given by the following expression:

$$
\begin{aligned}
& L_{20} \approx \gamma L_{S}+\rho L_{R}+n L_{N} \\
& \gamma+\rho+n=1(100 \%)
\end{aligned}
$$

Where $L_{S}, L_{R}$ and $L_{N}$ are the respective luminances from sky, road and surroundings (neighbourhood) within the $20^{\circ}$ cone and $\gamma, \rho$ and $n$ are their relative percentages.

Once the values of luminance have been calculated, the relevant illuminance necessary under the tension structure is given by the following expression [13]:

$$
E=\frac{L \pi}{\rho B \mu}
$$

where $E$ is the illuminance, $L$ the luminance, $\rho$ the reflectance of the road surface, $B$ the utilization factor and $\mu$ the maintenance factor. For the tunnel considered in this work, we have taken $\rho=0.2, B=0.8$ and $\mu=1$ as the most realistic approach.

The actual values of illuminance under the tension structure have been measured with a fully cosine corrected digital luxmeter HT172 which can measure illuminances within a wide range with a very good accuracy.

\section{Results}

For one road tunnel like the object of this work, depending on the maximum speed considered, the length of threshold zone can be $63 \mathrm{~m}$ or $97 \mathrm{~m}$ for maximum vehicle speeds of 80 and $100 \mathrm{~km} / \mathrm{h}$ respectively.

Depending on such length, the $L_{20}$ method, described in section 2 above, has different photometrical requirements. In Table I below the respective values for $L_{t h}$ and the mean illuminance are given for maximum speeds of 80 and $100 \mathrm{~km} / \mathrm{h}$

\begin{tabular}{||c|c|c|c||}
\hline $\begin{array}{c}\text { MAXIMUM } \\
\text { SPEED } \\
(\boldsymbol{K M} / \boldsymbol{H})\end{array}$ & $\begin{array}{c}\text { LENGTH } \\
(\boldsymbol{M})\end{array}$ & $\begin{array}{c}\mathbf{L}_{\mathbf{T H}} \\
\left(\boldsymbol{C D} / \boldsymbol{M}^{2}\right)\end{array}$ & $\begin{array}{c}\mathbf{E}_{\mathbf{M}} \\
(\boldsymbol{L} \boldsymbol{U} \boldsymbol{X})\end{array}$ \\
\hline 100 & 97 & 560 & 10995 \\
\hline 80 & 63 & 402 & 7890 \\
\hline
\end{tabular}

Table I. - Length, luminance and illuminance for different maximum speeds in a road tunnel.

Measurements under the tension structure yield a mean illuminance $\mathrm{E}_{\mathrm{m}}=8355 \mathrm{lux}$. This value results from the average of 21 measurements performed in intervals of $1 \mathrm{~m}$ in the middle, right and left sides under tension structure.

If we compare this value with the requirements in Table I, we realize that, for a maximum speed of $80 \mathrm{~km} / \mathrm{h}$, no electrical lighting is necessary under the tension structure during daytime. On the other hand, for a maximum speed of $100 \mathrm{~km} / \mathrm{h}$, the illuminance measured under the tension structure corresponds to $76 \%$ of the necessary one. If we consider it in energetic terms, this means an energetic spare of $100 \%$ and $76 \%$ under the structure for 80 and $100 \mathrm{~km} / \mathrm{h}$ respectively.

These results are summarized in Table II below:

\begin{tabular}{|c|c|}
\hline $\begin{array}{c}\text { MAXIMUM SPEED } \\
(\text { KM/H })\end{array}$ & ENERGY SAVING (\%) \\
\hline 100 & 76 \\
\hline 80 & 100 \\
\hline
\end{tabular}

Table II. - Percentage of energy saving for different maximum speeds in a road tunnel. 


\section{Conclusions}

Transparent tension structures have proved to be an effective measure to achieve important energy savings for the lighting of road tunnels. Indeed, in this research, we have got energy savings between 76 and $100 \%$ under the tension structure that we have set in the gate of one tunnel in Granada (Spain). The target was to extend the threshold zone of the tunnel (that is, the one immediately after the gate) and use the sunlight because, in this zone, the lighting system demands the highest amounts of energy to help drivers get visually adapted to the photometric conditions of road tunnels.

Besides the savings in direct energetic costs, other important aspects must be considered. The most important ones are the huge spare in both, materials and environmental costs, that can be achieved extending the threshold zone of road tunnels by means of tension structures.

With regard to paragraph above, if we think in materials, such reductions $(76-100 \%)$ also correspond to the number of luminaries under the tension structure, each incorporating bulbs, ballasts, mechanical protections, wiring and so on. Furthermore, fewer luminaries correspond to a minor maintenance which, in the case of road tunnels is a rather expensive and dangerous task for both workers and users of the road.

The decrease in direct energy consumption and materials presented above directly means an important saving in environmental costs arising from the manufacturing processes and energy production. These costs are mainly $\mathrm{CO}_{2}$, water steam and other polluting agents emissions, industrial waste in dumpings and sea, recycling of bulbs of lum naries...

Anyhow, results above belong to a quite new line of research and they can be still improved by using tension structures manufactured with materials that can adapt the amount of light to the particular conditions of insolation, atmospheric weather etc.

\section{Acknowledgement}

This research work was carried out under the financial support provided by Spanish Ministry of Education and Science as part of the Research Projects BIA 2007-62595.

\section{References}

[1] Commission International de l'Éclairage (CIE), "Guide for the lighting of road tunnels and underpasses", CIE Publ. 88, $2^{\text {nd }}$ Ed, Vienna, 2004.
[2] Commission International de l'Eclairage (CIE), "Light as a True Visual Quantity: Principles of Measurement", Commission Internationale de l'Eclairage, Paris, 1978.

[3] J. Schanda, L. Morren, M. Rea, L. Rositani-Ronchi and P. Walraven, "Does lighting need more photopic luminous efficiency functions?", Lighting Res. Technol., Vol. 34, pp. 69-78, 2002.

[4] A.J. Lewy, T.A. Wehr, F.K. Goodwin, D.A. Newsome and S.P. Markey, "Light suppresses melatonin secretion in humans", Science, Vol. 210, pp. 1267-1269, 1981.

[5] J.S. Adler, D.F. Kripke, R.T. Loving and S.L. Berga, "Peripheral vision suppression of melatonin", $J$ Pineal Res Vol. 12, pp. 49-52, 1992.

[6] R.J. Reiter, "Mechanisms of cancer inhibition by melatonin", J. Pineal Res, Vol. 37, pp. 213- 214, 2004.

[7] A. Knutsson, "Health disorders of shift workers", Occup. Med. Vol. 53, pp. 103- 108, 2003.

[8] S. Davis, D.K. Mirick and R.G. Stevens, "Night shift work, light at night, and risk of breast cancer", J. Natl. Cancer Inst. Vol. 93, pp. 1557-1562, 2001

[9] P. Blaser and H. Dudli, "Tunnel lighting : Method of calculating luminance of access zone $\mathrm{L}_{20}$ ", Lighting Res. Technol., Vol. 25, pp. 25-30, 1993.

[10] F. Vila Arroyo, "Iluminación de túneles en función de su ubicación y características", IV Simposium Nacional de Alumbrado, Barcelona, 1977.

[11] D.A. Schreuder, "Tunnel entrance lighting: a comparison of recommended practice", Lighting Res. Technol. Vol. 3, pp. 274-278, 1971.

[12] W. Adrian, "Investigations on the required luminance in tunnel entrances", Lighting Res. Technol. Vol. 14, pp. 151$\underline{159,1982 .}$

[13] G. Parise, L. Martirano and S. Pierdomenico, "An adaptive criterion o design the lighting system in the road tunnels", 42nd IEEE-IAS Annual Meeting, pp. 1244-1248, 2007. 